\title{
Douglas Diegues: metapoesia e outras metas
}

\author{
Wellington Furtado Ramos \\ Universidade Federal de Mato Grosso do Sul (UFMS), \\ Campo Grande, Mato Grosso do Sul, Brasil \\ furtado.ramos@ufms.br
}

DOI: http://dx.doi.org/10.21165/el.v46i3.1709

\begin{abstract}
Resumo
Este artigo apresenta a análise de alguns sonetos do poeta brasileiro contemporâneo Douglas Diegues a partir da seleção de poemas em que o fazer metapoético se manifesta como condição sine qua non do projeto estético do autor. Partindo da noção de metapoesia, verifica-se que a consciência de um fazer poético em processo se dá em Diegues em diversos níveis: pela atualização da forma clássica soneto, em sua variante shakespeariana; pela criação e utilização de uma língua mestiça, o portunhol selvagem (portunhol salbaje); pela recorrência de algumas figuras em seus poemas, como o "esperma" e a "belleza"; pelo uso crítico das experiências cotidianas em prol de uma obra cuja integridade cria um estilo à la Diegues. Desse modo, buscou-se verificar em que medida a produção de Diegues destaca-se e diferencia-se da produção poética brasileira contemporânea por meio das experimentações da e na linguagem.
\end{abstract}

Palavras-chave: poesia brasileira contemporânea; Douglas Diegues; metapoema.

\section{Douglas Diegues: metapoetry and other issues}

\begin{abstract}
This article presents the analysis of some sonnets of the Brazilian contemporary poet Douglas Diegues from the selection of poems in which the making of metapoetry is manifested as a sine qua non condition of the aesthetic project of the author. Following the metapoetry concept, it appears that the awareness of a poetic making process takes place in Diegues' poems at several levels: the update of the classic sonnet form in his Shakespearean variant; the creation and use of a mixed language, portunhol selvagem (portunhol salbaje); the recurrence of some figures in his poems, such as "esperma" ("sperm") and "belleza" ("beauty"); the critical use of everyday experiences in favor of a work whose integrity creates a style à la Diegues. Thus, we sought to verify to what extent the production of Diegues stands out and differs from the Brazilian contemporary poetic production through the experimentations in and with language.
\end{abstract}

Keywords: Brazilian contemporary poetry; Douglas Diegues; metapoetry.

La poesia debe ser como el amor. asunto raro de bichos raros de largos dedos sensitivos

La poesia debe ser como el amor, refinada y violenta y que haga daño y muerda sin llegar a romperse ni a romper

Pero a veces la poesia debe llegar más lejos que el amor y más lejos que todo

Y romper cosas

(Montserrat Álvarez) 


\section{Introdução}

Sem abandonar a perspectiva lírica que nos remete aos ecos da origem da poesia como manifestação cultural humana centrada em elaborações subjetivas e sentimentais/sensitivas - no poema de Montserrat Álvarez materializada pela imagem da poesia como amor -, nos é dado a ler que a poesia deve chegar mais longe que o amor, deve chegar mais longe de tudo, deve romper coisas.

Tomando como mote o próprio poema, somos levados a crer que a poesia, no seu compromisso de ir além, de algum modo tem como dever uma espécie de retorno à sua perspectiva ancestral e primitiva por meio de uma sensibilidade animal refinada $y$ violenta que é caso para bichos raros de largos dedos / sensitivos, em clara alegoria à imagem do poeta, ente que lambe as palavras e depois se alucina, nas palavras de Manoel de Barros.

Caberia ao poeta, então, buscar pela poesia (em favor dela, e por meio dela) a potência de ruptura da ordem das coisas e do mundo. Sendo a poesia da ordem da linguagem, é por meio da linguagem que a poesia pode implodir seus códigos e estruturas para ir além, num exercício crítico, reflexivo e, mais propriamente, metalinguístico; afinal, conforme Barthes (1996, p. 17), "é no interior da língua que a língua deve ser combatida".

Não por acaso, o poema que nos serve de epígrafe tem como título Ars poetica, e é exatamente sobre a arte poética, sobre o seu fazer crítico e reflexivo que se objetiva tangenciar a seguir. É nesse domínio do fazer poético que se volta sobre si mesmo, em um sentido estrito, que se concentrará esta análise, em que se discute a produção do poeta Douglas Diegues, a partir da seleção de poemas e entrevistas em que o fazer metapoético se manifesta como condição sine qua non do projeto estético construído pelo autor.

Para efeito de organização, o texto está dividido em itens que buscam traçar um percurso que vai do mais geral, aspectos da poesia brasileira contemporânea, ao mais específico, as relações entre a metapoesia de Douglas Diegues e a experiência na linguagem.

\section{Poesia brasileira contemporânea: panorama crítico e de produção}

Pensar a poesia brasileira contemporânea implica, necessariamente, uma série de questionamentos acerca do estatuto dessa produção: como se constitui? Quem são os poetas contemporâneos e a que se dedicam? O que é o "contemporâneo"? A esse respeito, André Dick (2012) em seu artigo intitulado "Poesia brasileira contemporânea: algumas notas" recupera a dialética entre tradição e ruptura como mote para pensar o papel do poeta contemporâneo como aquele que "fingindo ou não, [...] lida com uma verdade, ou seja, lida com uma experiência de linguagem, ligada a toda uma tradição que o antecede e o circunda" (DICK, 2012, p. 99, grifo do autor). Para tal, o autor parte da noção de poesia "pós-utópica", de Haroldo de Campos, tal qual se lê em "Metalinguagem e outras metas" (1992): 
Nessa acepção, a poesia viável do presente é uma poesia de pós-vanguarda, não porque seja pós-moderna ou antimoderna, mas porque é pós-utópica. Ao projeto totalizador da vanguarda, que, no limite, só a utopia redentora pode sustentar, sucede a pluralização das poéticas possível. Ao princípio-esperança voltado para o futuro, sucede o principio-realidade, fundamento ancorado no presente. [...] Esta poesia da presentidade, no meu modo de ver, não deve todavia ensejar uma poética da abdicação, não deve servir de álibi ao ecletismo regressivo ou à facilidade. Ao invés, a admissão de uma 'história plural' nos incita à apropriação crítica de uma 'pluralidade de passados', sem uma prévia determinação exclusivista do futuro (CAMPOS, 1992, p. 268-269, grifo do autor).

Diante, portanto, de uma tensão entre modernidade e vanguarda, a poesia concreta, por exemplo, se localizaria em um estatuto mais "sincrônico" que não necessariamente visava ao futuro, mas "como a modernidade, ela tentava prever um 'permanente presente', sobretudo no rigor e na síntese de críticas, atribuindo importância a um paideuma de autores, localizando-os sincronicamente no tempo" (DICK, 2012, p. 105) enquanto a poesia marginal que a sucedera teria ficado conhecida justamente "por não querer conhecer especialmente a tradição, por manter em dúvida o trabalho com a linguagem, com sua aversão a autores como João Cabral" (DICK, 2012, p. 109).

Essa dinâmica que envolve o reconhecimento ou a filiação à tradição chegaria ao limite de uma divisão entre dois grandes ramos da produção contemporânea: um deles mais próximo à poesia "cerebral" de João Cabral de Melo Neto e outro mais próximo de Carlos Drummond de Andrade (DICK, 2012, p. 115). Apesar disso, André Dick enxerga que a produção contemporânea se faz mais heterogênea e diversificada do que essa dicotomia pode parecer. Segundo ele,

Pode-se pensar que a maioria dos poetas contemporâneos respeita os mais diversos caminhos da poesia - o que não significa, caso se saiba filtrar, um vale-tudo. Não há mais o preconceito que havia de uma geração com outra. O modernismo foi mais assimilado na dicção de alguns, a poesia concreta ou a poesia marginal na dicção de outros, mas todos esses elementos se misturam às vezes - e, quando efetivos, de maneira equilibrada. Não costuma haver uma negação à leitura de poetas tão diversos entre si, nem de determinadas correntes, mesmo que se escolham alguns caminhos e se discorde de outros (DICK, 2012, p. 116).

Ou seja, retomando Haroldo de Campos, o poeta conscientemente acessa aquela "história plural" e seleciona da tradição o que lhe interessa de modo crítico, ao criar no interior dos poemas a "pluralidade de passados" a que remetem ou que criam sem, no entanto, estar submetidos a uma lógica totalizante das vanguardas e àquele projeto de futuro. No que diz respeito à escolha de procedimentos, por exemplo, Dick (2012, p. 117) completa:

Alguns poetas ainda adotam um caminho mais clássico: utilizam o soneto, mas de forma moderna, autoirônica. Imagens e figuras mitológicas são revistas por outros poetas. A sintaxe pretendida costuma ser alternada; o número de versos em estrofes varia de poema para poema; o olhar sobre a sociedade, que se converteu certa época em populismo, acontece de maneira menos retórica e discursiva, optando por imagens mais objetivas, fragmentadas e esvaziadas de intenção partidária. Pelo conhecimento da 
teoria da literatura, muitos poetas naturalmente entendem que o caminho que estão desbravando não é original.

Desse modo, verifica o autor que a tensão entre modernidade e vanguarda, tradição e ruptura ou entre "movimentos" como concretismo e poesia marginal possibilitaram ao poeta contemporâneo uma diversidade de técnicas, procedimentos e estratégias discursivas que abrem a produção atual à pluralização de poéticas. Uma série de autores coadunou a consciência linguística a uma poesia de experiência no sentido do "princípio realidade", ou seja, "junto com a tradição, esses poetas souberam colocar suas experiências em seus poemas - não no sentido corrente, porém, de fazerem confissões via poesia - e tornaram sua ligação com a linguagem mais consciente" (DICK, 2012, p. 118, grifo do autor).

Nesse universo plural de poéticas e autores, chama-nos a atenção a produção de Douglas Diegues, carioca, nascido em 1965. Poeta que transita entre o Rio de Janeiro, Curitiba, Campo Grande, Ponta Porã e Assunción/Paraguai, a produção de Douglas Diegues tem recebido razoável apreciação crítica, sendo ele respeitado pelo trabalho poético-etnográfico com a poesia mbyá-guarani e pela atenção à sua obra dispensada por intelectuais respeitáveis, como Ana Cecilia Olmos, Ítalo Moriconi, Myriam Ávila e Rosana Zanelatto.

Segundo Myriam Ávila (2012), parte dessa atenção não se deve tão somente à dimensão intrínseca da obra poética de Douglas, mas também ao "tom declamatório, conclamatório e até panfletário de muitos de seus poemas, em que o eu é sempre um eu para o mundo e diante do mundo" (ÁVILA, 2002, p. 7), o que nos remete diretamente à proposição do "princípio realidade", tal qual visto em Haroldo de Campos. Conta o poeta que queimou mais de 300 poemas de sua primeira fase até chegar à língua que procurava para se exprimir, já que a sintaxe do português lhe endurecia os versos (ÁVILA, 2002, p. 10).

O primeiro livro de Diegues foi publicado pela Travessa dos Editores, em 2002. Intitulado Dá gusto andar desnudo por estas selvas, a obra é composta por sonetos sem título, escritos na língua pela qual Douglas será (re)conhecido: o portunhol selvagem (portunhol salbaje). Após essa publicação, o autor passou a ter seus livros editados de modo alternativo pelas editoras kartoneras, um coletivo de editores que produzem livros confeccionados manualmente, a partir de fotocópias do miolo e da confecção de capas artesanais, que conferem caráter único a cada unidade.

O portunhol selvagem é "encarnado" por Douglas Diegues não somente em sua produção literária stricto sensu; é possível verificar que o autor emprega o uso dessa língua também em seu blogue e nas entrevistas que concede. Língua livre, "sem regra, gramática ou ordem" (AVILA, 2012, p. 10), o portunhol selvagem de Diegues é uma interlíngua que se utiliza das estruturas sintáticas da língua portuguesa e da língua espanhola atreladas aos vocábulos da língua guarani e da língua inglesa, em uma mixagem típica do ambiente fronteiriço ao qual o poeta se vincula geográfica e afetivamente, a tríplice fronteira (ou triplefronteira, nas palavras de Douglas) entre Brasil, Paraguai e Bolívia. 
Filiado a uma tradição de hibridação de línguas (como nas obras de Alexandre Ribeiro Marcondes Machado, Paulo Leminski - Catatau/1975 e Haroldo de Campos Galáxias/1984), Joca Reiners Terron (2014) afirma que o portunhol selvagem de Diegues está mais diretamente relacionado à produção de Nestor Perlongher, poeta argentino, e de Wilson Bueno, escritor brasileiro, autor de Mar Paraguayo (1992). Segundo Reynaldo Damazio (2014, p. 50),

O portunhol selvagem (ou selbaje) inventado e praticado por Douglas Diegues não tem a pretensão de ser uma língua universalista, ainda que poética, mas talvez provocar um estranhamento no atrito de dois idiomas próximos, que facilmente se confundem. Além disso, a experiência com essa linguagem artificial e caótica também incorpora o confronto de culturas, vozes e sotaques na América Latina, onde as fronteiras e o trânsito entre os países são fonte de múltiplos intercâmbios, misturas e contaminações. Não se trata de um processo de globalização, como às vezes imaginam os analistas mais precipitados e zelosos do determinismo econômico, mas de carnavalização, ou de reinvenção anárquica de elementos culturais, históricos, antropológicos, sociais e, por fim, estéticos.

Nesse sentido, o portunhol selvagem ganha como língua dentro de uma lógica que é, por vezes, errática; como jogo proposto, a coerência e a correção léxica perdem sentido nesse universo de embaralhamento de sentidos. O bom senso é subvertido em favor de uma aproximação com as coisas cotidianas, com a fala e com os improvisos de comunicação, regados por uma postura de ousadia. Nas palavras de Diegues, o portunhol selvagem é "una mescla de bosta y algodon sin data de vencimento / para este dia banal, caro, superfaturado, en la balanza comercial" (DIEGUES, 2002, p. 35).

Essa postura deliberada, que carrega, simultaneamente, uma dimensão de consciência linguística aliada à experiência, materializa-se na poesia de Douglas constantemente pela construção de metapoemas, ou seja, o fazer poético é trazido à tona pelo poema por meio das escolhas formais, do jogo com a linguagem e pela recorrência de alusões ao fazer poético.

\section{Metapoesia}

Segundo Adalberto Müller Jr. (1996, p. 14),

Podemos definir um metapoema como um poema que focaliza o próprio código poético, pressupondo-se de antemão a existência de tal código, distinto do código da língua, sobre o qual se apoia. Ou ainda, a metapoesia pode ser definida como uma 'teoria do poético embutida auto-reflexivamente no poema'. Um texto que se volta não somente para a mensagem - o que, segundo Jakobson, caracteriza a função poética - mas para a explicitação e a reflexão sobre o "como" a mensagem é veiculada no poema.

Essa consciência já é explícita no primeiro (1) poema publicado em Dá gusto andar desnudo por estas selvas (2002), primeiro livro publicado por Diegues. Vejamos:

(1) burguesa patusca light ciudade morena

el fuego de la palavra vá a incendiar tua frieza

ninguém consigue comprar sabedoria alegria belleza

vas a aprender agora con cuanto esperma se hace un buen poema 


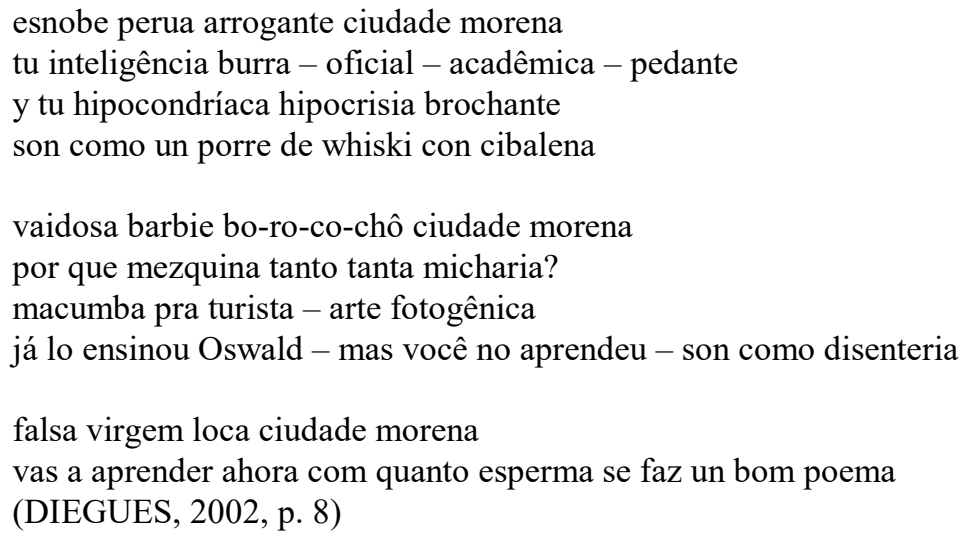

Como se lê, o eu-lírico posiciona-se como que didaticamente ao enunciar por meio de um verso que se repete na primeira e quarta estrofe do soneto: "vas a aprender ahora con quanto esperma se faz un bom poema". Não se pode deixar de notar que a figura do "esperma" está diretamente ligada à ideia de "fogo da palavra" que é preciso para incendiar a frieza da "ciudade morena"; o bom poema precisa de "esperma", precisa ser fecundado, já que "já lo ensinou Oswald - mas você no aprendeu".

Além disso, a recorrência a uma forma clássica como o soneto já é índice de uma seleção e posicionamento na tradição, no entanto, há um resgate do soneto shakespeariano, ou seja, aquele que contém 14 versos distribuídos em três estrofes de quatro versos e um dístico final. Segundo Ávila (2012, p. 21),

A forma dos sonetos permanece a mesma nos três livros [...] Essa organização dos versos se mostra especialmente adequada ao tom discursivo de Douglas por permitir a conclusão em epigrama, que funciona como espécie de avaliação final ou arremate do tema tratado.

Em outro soneto (2), vemos mais uma vez a figura do "esperma" como fonte de fecundidade para o poema. Também neste, o dístico final serve de arremate e cria um tom de arte poética no soneto, que também conta com a referência explícita a um autor da literatura portuguesa, Antonio Lobo Antunes. Convém notar como o poeta, ao enunciar seu nome próprio, coloca-se em relação simétrica ao autor canônico português, mesmo que a informação implique em ironia, uma vez que "poco importa quem hoy canta la pelota en la gran feira literária brasileira". A literatura fecundada, "mucho más berdadeira", está fundada nas verdades inventadas, sendo esta a relação que o eu-lírico enxerga na proximidade com a tradição lusa. Também as imagens abjetas, do esperma, da urina - neste poema, como as da merda - em outros supracitados, parecem ser férteis para a aproximação com a tradição escolhida, crítica e conscientemente, já que recorrentes nas obras de Lobo Antunes como As naus, Os cus de Judas e A ordem natural das coisas, para citarmos algumas.

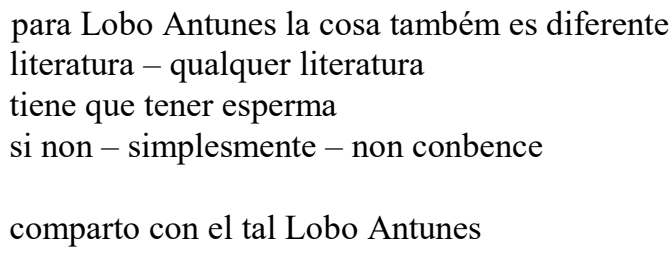


de esa verdade inbentada -

sin esperma la literatura

non fede ni cheira ni nada

literatura - escritura - cuarquier literatura

sin esperma

parece orina - frase impostada - conbersa

mole - enganación - guevo falso - falsa locura

Douglas Diegues ou Lobo Antunes, poco importa quem hoy canta la pelota en la gran feira [literária brasileira

literatura con esperma es mucho más berdadeira.

(DIEGUES, 2002, p. 5)

No próximo soneto (3), a disposição dos vocábulos em forma de enumeração traz renovação à poesia, que "é morta mas continua viva", por meio da escolha de diferentes palavras que designam o órgão sexual feminino. Essa escolha está atrelada ao campo de "fecundidade" que já foi visto nos sonetos anteriores por meio da alusão ao "esperma". Além disso, ao recolher registros da fala cotidiana em português, espanhol e guarani, temos a criação do espaço interlinguístico do qual tratamos anteriormente que, simultaneamente, remete à construção do poema e à experiência:

(3) xota buraco dentado buçanha buceta

cona papaya racha

tatú buza babaca

perereca concha conchita concheta

eis algunos de los nombres del sexo de las meninas

que hace miles de anos inventando viene el povo

que bota esplendidos hovos

con los que posso inbentar inéditas rimas

la poesia está morta mas continua viva

mesmo que uns la queiram toda certinha

sin gosma íntima sin esperma sin suíngue sin chupetinha

y sin la endorfina verbal dum glauco dum back dum leminski dun manoel dum piva

para compensar toda essa literatura morta

restam al menos el pau bién duro dentro de la carnuda xoxota

(DIEGUES, 2002, p. 6)

Além disso, há a referência explícita a uma tradição literária, nomeada: Glauco Mattoso, Sylvio Back, Paulo Leminski, Manoel de Barros e Roberto Piva. Segundo Ávila (2012, p. 16-17),

A montagem desse painel de precursores é um jogo de desejo. Temos aí, em primeiro lugar, os poetas - contemporâneos ou não - que o novo poeta reverencia de forma especial ou escolhe como seus patronos. No caso de Douglas, existe uma confessa admiração pelo conterrâneo Manoel de Barros, citado algumas vezes em seus versos e, frequentemente, em seus depoimentos. Dono de uma dicção inconfundível, Manoel de Barros pode provocar nos candidatos a escritores uma identificação tal que os leva a imitar de forma mais ou menos diluidora o estilo do poeta mais velho. Não é o que acontece com Douglas. Nada de sua admiração pela simplicidade e pela redescoberta das coisas em Manoel de Barros transparece em sua poesia. Seu mundo é o das coisas 
transformadas pela ação dos processos industriais e sociais sob a batuta das relações econômicas. Raramente aparecem de forma nostálgica, elementos naturais que lembram uma antiga harmonia entre homem e mundo.

No que diz respeito a esse campo da experiência ligado às relações sociais e econômicas particulares da triplefronteira que se relaciona à produção de Diegues, é preciso pensar como se dá esse uso da experiência em relação à consciência poética própria do fazer metalinguístico.

Em "O lugar da poesia brasileira contemporânea: um mapa da produção", Sylvia Helena Cyntrão (2008, p. 83) busca verificar aspectos da produção poética brasileira partindo da noção de que "o texto poético é um produto cultural que trabalha com a transfiguração do real, manipulando um capital simbólico coletivo", ao apresentar os resultados parciais de uma pesquisa quantitativa que procedeu ao levantamento de 100 autores e 3 mil poemas produzidos e publicados no Brasil no período de 1990 a 2007. Para verificar os usos e escolhas dos poetas contemporâneos quanto à estrutura textual, a autora selecionou como parâmetros os aspectos de: formalização; tipologia enunciativa: narrativa, figurativa, metapoética; funções agregadas à função poética: emotiva, fática, metalinguística, referencial; subjetividade enunciativa (eu-poético) e apresenta:

No que diz respeito à função de linguagem que está ligada à função poética, a que prevalece é a emotiva, aquela vista do prisma do emissor. É interessante observar que, a despeito de toda a fragmentação do sujeito na pós-modernidade, há uma tentativa de recuperação dessa inteireza perdida, como um movimento em direção à integração das partes, e isso é representado pela recorrência ao pronome "eu", explícito ou não (CYNTRÃO, 2008, p. 6).

E, mais especificamente ao que nos interessa, completa:

A função metalinguística apresentou uma baixíssima frequência, talvez fruto do esgotamento da força gravitacional da racionalização na poesia, devido à intensa necessidade de representar, de alguma forma, o "eu" esfacelado. Nesse item, também podemos incluir a prevalência da tematização sentimental. A leve predominância da função emotiva sobre a função referencial estaria a indicar que o discurso poético (ainda) não se contaminou das reestruturações ou re-escalonamentos próprios da sociedade pós-moderna, que tendem ao domínio da instância econômica sobre os diversos campos da vida social. Estaria a indicar que o poeta quer preservar sua subjetividade das infectações discursivas que permitem que se misture o público e o privado (CYNTRÃO, 2008, p. 86).

Apesar de não nos ser dado a conhecer no artigo supramencionado se o poeta Douglas Diegues consta do escopo da pesquisa empreendida, nos chama a atenção a dissonância entre a produção de Diegues e esse universo detectado pela autora. Havendo a possibilidade de que a produção de Diegues não tenha sido abrangida, quer seja porque, majoritariamente, suas publicações circulam em um mercado editorial alternativo por meio dos coletivos de cartoneiras, ou porque Dá gusto andar desnudo por estas selvas (2002) foi publicado por uma editora com menor expressão no mercado editorial brasileiro, é relevante considerar o quanto sua poesia desvia e se singulariza nesse universo, uma vez que, além da elaboração metapoética, também põe em xeque esse "domínio da instância econômica sobre os diversos campos da vida social", não de 
modo "contaminado" como esperava encontrar Cyntrão (2008, p. 86), mas como voz poética que se põe à parte dessas questões com lucidez para criticá-las como se lê, por exemplo, desde o primeiro soneto de Dá gusto...:

(4) burguesa patusca light ciudade morena

el fuego de la palavra vá a incendiar tua frieza

ninguém consigue comprar sabedoria alegria belleza

vas a aprender agora con cuanto esperma se hace um buen poema

esnobe perua arrogante ciudade morena

tu inteligência burra - oficial - acadêmica - pedante

y tu hipocondríaca hipocrisia brochante

son como un porre de whiski con cibalena

vaidosa barbie bo-ro-co-chô ciudade morena

por que mezquina tanto tanta micharia?

macumba pra turista - arte fotogênica

já lo ensinou Oswald - mas você no aprendeu - son como disenteria

falsa virgem loca ciudade morena

vas a aprender ahora com quanto esperma se faz un bom poema

(DIEGUES, 2002, p. 8)

Ao adjetivar a "ciudade morena" como "burguesa patusca", o eu-lírico parece revelar sua posição contrária a esse status quo que faz da cidade fria e que necessita do fogo da palavra para incendiá-la; essa acusação perante a lógica de consumo e que diz respeito a níveis de domínio da instância econômica sobre a vida social se apresenta como negativa uma vez que, do ponto de vista da poesia, é preciso "esperma" já que "sabedoria alegria belleza" não se compra, ou seja, o caráter mais profundo e essencial que caberia ao poético não faz sentido nessa dinâmica que "mezquina tanto tanta micharia".

Assim, também em seu segundo livro composto de sonetos, Uma flor na solapa da miséria (2005), outras imagens dialogam simultaneamente com esse questionamento da tensão entre o mais essencial e o mais aparente, entre o mais poético e o mais prosaico, que tem subjacentes alguns temas como os do soneto anterior. No soneto a seguir, essa relação entre lógica de consumo, beleza e poesia se dá pela junção de pares antitéticos que, conforme já exposto, são arrematados em tom crítico no dístico final:

(5) belleza pública bersus belleza íntima

belleza bisible bersus belleza que ninguém bê

belleza dolarizada bersus belleza gratuita

belleza cozida bersus belleza frita

belleza antigua bersus belleza nova

belleza viva versus belleza morta

belleza magra bersus belleza gorda

belleza em berso y en prosa

belleza sabaje bersus belleza civilizada

belleza de dentro bersus belleza de fora

beleza simples bersus belleza complicada 
este mundo está ficando cada vez mais horrible

quase ninguém consegue mais ver la belleza invisible

(DIEGUES, 2005, p. 4)

O eu-lírico, pouco "eu" e pouco "lírico", está escondido no corpo do poema por meio da construção paratática dos versos e se dá tão somente de modo virtual pela inferência na leitura do segundo verso da última estrofe. Se nas três primeiras estrofes o uso da parataxe coloca as ideias e imagens apresentadas em um mesmo nível, sem apresentar um julgamento explícito e hierarquizante de modo a apenas gerar tensão interna pela repetição do vocábulo "bersus", aparentemente, o eu-lírico subjacente que se manifesta no dístico final é um dos poucos a enxergar essa "beleza invisible" que "quase ninguém consegue mais ver" mas, como se leu no poema anterior, já que a "belleza" não é mercadoria disponível, fica implícita essa força e compromisso quase ético de que é preciso ensinar "ahora con quanto esperma se faz un bom poema".

\section{Considerações finais}

Como foi possível verificar brevemente, a consciência do fazer poético em Douglas Diegues se dá em diversos níveis: pela atualização da forma clássica do soneto em sua variante shakespeariana; pela criação e utilização de uma língua mestiça, fruto da mescla entre português, espanhol, guarani e inglês; pelas figuras sobre a matéria de sua poesia, para usar uma expressão manoelina, como o "esperma"; pelo uso crítico da experiência cotidiana e fronteiriça (geográfica, econômica e linguisticamente) na construção de poemas. Nas palavras de Douglas:

(6) Por que escrebo?

Escrebo para ficar menos mesquinho

belleza de lo invisible

non tem nada a ver com berso certinho

en el culo de qualquer momento

escreber pode ser mais que apenas ir morrendo

la belleza de lo invisible

non se pudre con el tempo

la bosta dos elefantes seca verde clara dura

es altamente inflamáble - dá uma llama bem pura

nunca se termina de aprender a transformar bosta em luz y

otros desenganos -

todos fomos bellos quando teníamos 4 anos

hoje la maioria solo se preocupa com sus narizes

su esperma, su bosta, su lucro, sus missíles

Tomando por base os poemas lidos, é possível verificar que não se trata necessariamente de uma absorção ou contaminação na poesia de Diegues daquilo que Cyntrão (2008, p. 86) chama de "reestruturações ou re-escalonamentos próprios da sociedade pós-moderna"; parece-nos, ao contrário, que esse eu-lírico apresentado nos dois poemas está além dessa condição, de modo a enxergá-la criticamente. Além disso, é possível notar o caráter orgânico da obra de Diegues uma vez que esse diálogo entre 
poemas de livros diferentes vai além dos exemplos que aqui expomos e que nos limitamos a elencar por força de restrição espacial.

\section{REFERÊNCIAS}

ÁVILA, Myriam. Douglas Diegues: por Myriam Ávila. Rio de Janeiro: EdUERJ, 2012. (Ciranda da Poesia)

BARTHES, R. Aula. Tradução de Leyla Perrone-Moisés. São Paulo: Cultrix, 2004.

CAMPOS, H. de. Metalinguagem e outras metas. São Paulo: Perspectiva, 1992.

CYNTRÃO, S. H. O lugar da poesia brasileira contemporânea: um mapa da produção. Ipotesi, Juiz de Fora, v. 12, n. 2, p. 83-92, jul./dez. 2008.

DAMAZIO, R. A fala da fronteira. Nossa América. Revista do Memorial da América Latina, ed. 51, p. 50, 2. sem./2014.

DICK, A. Poesia contemporânea brasileira: algumas notas. Eutomia, ed. 9, ano V, p. 98129, jul. 2012.

DIEGUES, D. Dá gusto andar desnudo por estas selvas. Curitiba: Travessa dos Editores, 2002.

. Tudo. Santa Maria: Vento Norte Cartonero, 2015.

. Uma flor na solapa da miséria. Assunción: Heloisa Cartonera, 2005.

MÜLLER JR., A. A metalinguagem na poesia brasileira contemporânea. Cerrados, Brasília, n. 5, p. 13-23, 1996.

TERRON, J. R. Rebelião metafísica: a invenção do portunhol selvagem. Nossa América. Revista do Memorial da América Latina, ed. 51, p. 46-49, 2. sem./2014.

Recebido em: 02/09/2016

Aprovado em: 29/05/2017 